This item was submitted to Loughborough's Research Repository by the author.

Items in Figshare are protected by copyright, with all rights reserved, unless otherwise indicated.

\title{
Educational landscapes: Nature, place and moral geographies
}

PLEASE CITE THE PUBLISHED VERSION

https://doi.org/10.1111/geoj.12305

\section{PUBLISHER}

(c) Royal Geographical Society (with the Institute of British Geographers). Published by Wiley.

\section{VERSION}

AM (Accepted Manuscript)

\section{PUBLISHER STATEMENT}

This is the peer reviewed version of the following article: HICKMAN DUNNE, J.L. and MILLS, S., 2019. Educational landscapes: Nature, place and moral geographies. Geographical Journal, DOI: 10.1111/geoj.12305, which has been published in final form at https://doi.org/10.1111/geoj.12305. This article may be used for non-commercial purposes in accordance with Wiley Terms and Conditions for Use of SelfArchived Versions

\section{LICENCE}

CC BY-NC-ND 4.0

\section{REPOSITORY RECORD}

Dunne, Joanne L. Hickman, and Sarah Mills. 2019. "Educational Landscapes: Nature, Place and Moral Geographies". Loughborough University. https://hdl.handle.net/2134/38347. 


\title{
Educational Landscapes: Nature, Place and Moral Geographies
}

\begin{abstract}
:
In this editorial introduction, we outline recent debates on geographies of education, specifically on themes of nature, place and outdoor landscapes. We argue for the need to extend these discussions due to the rising popularity and politicisation of educational encounters in outdoor landscapes, as well as their long-standing relationship to a series of moral geographies. We introduce the main focus of the five papers in this themed collection, and show how together, they add to our understanding of the spatialities and experiences of both formal and informal educational sites, through both historical and contemporary perspectives. We reflect on some of the themes that tie these papers together, the UK-based focus of this collection, and its wider geographical contributions.
\end{abstract}

Keywords: Nature, Education, Landscape, United Kingdom, Outdoor learning 


\section{Editorial Introduction}

\section{Educational Landscapes: Nature, Place and Moral Geographies}

This themed section explores outdoor landscapes as educational spaces, critically engaging with key concepts of nature, place and moral geographies. Geographers have previously explored both the historical connections amongst nature, education, rural space, adventure, childhood and youth (Philo 1992; Matless 1998 [2016]), and the contemporary use of the 'great outdoors' to foster 'life skills' in informal educational settings (Fjørtoft 2001; Mills \& Kraftl 2014). Indeed, research on the geographies of education has flourished in recent years (Holloway et al. 2010; Mills \& Kraftl 2016) as on-going work by geographers has considered the importance of the spatiality and experience of "formal education systems [...] and informal learning environments in homes, neighbourhoods, community organisations and workspaces" (Holloway and Jöns, 2012: 482). Geographers have also become a critical voice in destabilizing nature/childhood relationships and connections through a post-humanist approach (Taylor 2013; Pacini-Ketchabaw et al. 2016; Kraftl et al. 2018), revealing the complexities of children's relations with a more-than-human world. Against this backdrop, children's geographers in particular have focused on children and young people's diverse experiences of nature in educational environments (i.e. Merewether 2018; Mycock 2018). This work has indicated the need to consider the more material places and practices of everyday life which shape outdoor educational encounters. Consequently, this themed section extends this focus within the geographies of education to include the spatiality and experience of outdoor environments as part of both formal and informal educational sites and settings. It brings fresh attention to these debates through a series of distinct and instructive case-studies in order to examine a wider series of place-based moral geographies in educational spaces. In this editorial, we introduce the individual papers as well as highlighting some interconnecting themes and wider reflections on 'educational landscapes: nature, place and moral geographies'.

The papers in this themed section present a set of original empirically informed papers which combine a focus on educational spaces with wider debates in social and cultural geography on landscape, practice and (outdoor) mobilities (Merriman et al. 2008), as well as on theories of nature, embodiment and in/exclusion (Macpherson 2009; Tolia-Kelly 2007). The papers approach the concept of educational landscapes through both historical and contemporary 
perspectives, seeking to re-centre the (natural) 'physical' landscape in the work of geographies of education. Perhaps appropriately, given the multiplicity of roots which has given rise to the field of geographies of education (Holloway \& Jöns 2011), the papers in this collection bring together work from historical, social, cultural, and children's geographers whose research engages with ideas regarding education and learning. Taking 'educational landscapes' as a starting point but coming from a diverse range of perspectives, the contributing authors engage with long-standing debates in geography on theories of nature, landscape and place. All of the papers in this themed section focus on the United Kingdom, which was a deliberate intention in bringing together these contributions as a collective. Although clearly partial in terms of its geographical coverage, a distinct focus on the UK is incredibly timely given that encounters with nature and the outdoors has been driven up the social agenda in the UK in recent years, especially in relation to young people. This is a consequence of a series of interconnecting issues, including concerns over the reported decline of outdoor play due to myriad factors including urbanisation and the politics of play in times of austerity (Moss 2012) as well as wider fears over 'Nature Deficit Disorder' (Louv 2005) ${ }^{1}$. These broader issues however extend to encompass all ages and stages of the life cycle, through concerns over physical inactivity (Rowley et al. 2017) and corresponding diminished opportunities for human contact with nature (Hatig et al. 2014). These debates are playing out in a wide range of diverse international contexts across the globe (for work on diverse childhood-nature relations in India for example, see Hadfield-Hill and Zara 2019; or in Bolivia, see Malone 2016 on disrupting universalisms about children in nature). However in the UK at present, re-connecting with nature is deemed to offer a solution to part, or even all, of these societal concerns. Understanding people's changing, renewed, or re-framed engagements with outdoor environments is a necessary endeavour and this collection critically responds to these calls for greater use of outdoor environments in educational contexts. Indeed, an understanding of these changing underlying processes in the UK opens up the potential for more international relevance to the findings of the respective papers, notwithstanding their UK focus. The themed section also uncovers some of the historical antecedents underlying these contemporary relationships between nature, place and moral geographies, demonstrating how these have been shaped over time as well as space.

Francesca Church's paper provides a historical account of the Council for the Preservation of Rural England's (CPRE) cultures of education for children and young people in the 1930s (Church, 2019). Through the notion of 'amenity', Church focuses on nature study and school 
design as educational instruments through which young people were taught to appreciate amenity (of natural environments). The paper highlights how the CPRE mobilised its authority through formal education to train young people in citizenly practices relating to preservationism, and them as future citizens able to solve succeeding issues regarding countryside protection. Helena Pimlott-Wilson and Janine Coates' paper also considers how learning and education is orientated towards developing future 'citizen-workers', through a contemporary exploration of Forest School in England (Pimlott-Wilson and Coates, 2019). The authors challenge the dichotomy between informal and formal educational spaces by exploring how, through Forest School, alternative forms of education are being drawn into mainstream practices. In analysing primary school-aged children's perspectives on playing and learning, the paper highlights how learning and work are bound together within the space of the classroom, and engagements with Forest School challenge children's notions of learning through a lack of assessment, writing-based tasks, and confined bodily movements. Critically, this paper raises questions around equality of access, whereby a diversified curriculum which incorporates informal educational environments may only be available to those who attend well-performing and better-funded schools.

Notions of inequality of access in informal educational practices are also central to Jo Hickman Dunne's contribution, which critically discusses young people's corporeal interactions with outdoor environments through an outdoor education programme in the UK (Hickman Dunne, 2019). This paper proposes that through multiple bodily encounters, outdoor environments in the Outward Bound Trust became spaces of agency and alterity for young people. However, the empirical research also reveals tensions between structure and agency whereby particular 'bodily knowledges' and physical engagements are encouraged. Furthermore, Hickman Dunne demonstrates how affective registers of outdoor landscapes elicit a certain politics of power. This can act to exclude some young people from these education spaces, or alter the benefit and quality of their experience through marking them as 'out of place' through lack of experience or skill. This discussion of specific place-based encounters chimes with Ria Dunkley and Thomas Smith's paper, which considers ecopedagogic interventions within the educational landscape of the Brecon Beacons National Park in Wales (Dunkley and Smith, 2019). Through a study of 4-11 year olds taking part in a 'summer club', the authors propose the concept of 'geocoaching' as an analytical tool through which to understand outdoor pedagogic practices. Employing Dewsbury's (2015) 
concepts of habit and occupation, and Lorimer's (2003) analysis of 'the field', the paper argues that children and adults draw on a range of representational and non-representational memories and habits that transcend the rural idyll, to produce variations of 'the field' and 'the self'. For the authors, thinking about ecopedagogy as geocoaching provides a departure from the idealised moral geographies of environmental education, which assume that proximity to nature will result in the appropriate environmental stewardship.

Finally, the theme of representational landscapes is also central to Andy Morris' rich empirical account of the spectacle of the starling murmurations at Ham Wall nature reserve on the Somerset Levels (Morris, 2019). In this paper, which presents a shift in focus from purposeful adult-designed educational spaces for children and young people, Morris deconstructs the traditional nature/culture dichotomy commonly upheld through nature conservation practices. The paper highlights the reframing of the space of the nature reserve through the 'socialising' agency of people of all ages attracted to the murmuration, and the agency of starlings to reframe spaces beyond the reserve which act as spontaneous sites of natural-social encounter. Through this, Morris argues that the starling murmuration provides a model for communicating a more relational approach to human-nature relations, challenging conventions of an educational model which sees nature as spatially external to our social world.

This collection of papers are tied together through their focus on particular natural and outdoor spaces as settings for educational encounters. However, they also address some key interconnecting themes. The papers by Church, and Pimlott-Wilson and Coates, both focus on the contested geographies of (future) citizenship produced through particular educational practices. Hickman Dunne's paper also has implications for geographies of citizenship, through considering how the materiality of educational nature spaces projects a system of 'norms' onto young people's bodies. Although this paper specifically deals with the physicality of outdoor encounters, it hints at the particular type of citizenship practices (physical or otherwise) which educational natures engender. The papers by Dunkley and Smith, and Morris, push us to consider engagements with outdoor educational spaces and how personal and social encounters shape nature as an educational space, therefore presenting a challenge to critical interpretations of nature as an institution suffused with societal norms and values. 
Overall, this themed section centres outdoor environments within wider debates on the geographies of education, nature and moral geographies. Together, these five papers examine the opportunities and challenges of the 'place' of nature, through their critical examination of a range of educational spaces, practices and encounters in the UK. The broader themes and contributions of the papers have a wider reach, not least with the increasing politicisation of shifting educational landscapes across the globe.

\section{Acknowledgements}

We wish to extend our thanks to the Social and Cultural Geography Research Group \& Geographies of Children, Youth and Families Research Group of the RGS-IBG for sponsoring two linked sessions on 'Educational Landscapes: Nature, Place and Moral Geographies' at the 2017 RGS-IBG Annual Conference. Thanks to all of the presenters and audience members for their contributions to the discussion.

\section{References}

Church, F. (2019). Amenity as educator: Geographies of education, citizenship, and the CPRE in 1930s England, The Geographical Journal, 185, xxx-xxx.

Dewsbury, J. D. (2015). Non-representational landscapes and the performative affective forces of habit: from 'Live' to 'Blank'. Cultural Geographies, 22(1): 29-47.

Dunkley, R.A., \& Smith, T.A. (2019). Geocoaching: Memories and habits of learning in practices of ecopedagogy, The Geographical Journal, 185, xxx-xxx.

Fjørtoft, I. (2001) The natural environment as a playground for children: the impact of outdoor play activities in pre-primary school children. Early Childhood Education Journal 29 (2): 111-117.

Hadfield-Hill, S. and Zara, C. (2019) Complicating childhood-nature relations: Negotiated, spiritual and destructive encounters, Geoforum 98: 66-74.

Hartig, T., Mitchell, R., \& Frumkin, H. (2014). Nature and Health. Annual Review of Public Health, 35: 207-228.

Hickman Dunne, J. (2019). Experiencing the outdoors: Embodied encounters in the Outward Bound Trust, The Geographical Journal, 185, xxx-xxx.

Holloway, S. L., \& Jöns, H. (2012). Geographies of education and learning. Transactions of the Institute of British Geographers, 37(4): 482-488.

Holloway, S. L., Hubbard, P., Jöns, H., \& Pimlott-Wilson, H. (2010). Geographies of education and the significance of children, youth and families. Progress in Human Geography, 34(5): 583-600. 
Kraftl, P., Balastieri, J., Campos, A., Coles, B., Hadfield-Hill, S., Horton, J., Soares, P., Vilanova, M., Walker, C. and Zara, C. (2018, online early) (Re)Thinking (Re)Connection: Young People, 'Natures' and the Water-Energy-Food Nexus in São Paulo State, Brazil. Transactions of the Institute of British Geographers.

Lorimer, H. (2003). The geographical field course as active archive. Cultural Geographies, 10(3): 278-308.

Louv, R. (2005). Last Child in the Woods: Saving our children from nature-deficit disorder. New York: Algonquin Books.

Macpherson, H. (2009) The inter-corporeal emergence of landscape: negotiating sight, blindness and ideas of landscape in the British countryside Environment and Planning A, 41 (5): 1042-1054.

Malone, K. (2016) Theorizing a child-dog encounter in the slums of La Paz using posthumanistic approaches in order to disrupt universalisms in current 'child in nature' debates, Children's Geographies 14 (4): 390-407.

Matless, D. (1998) [2016] Landscape and Englishness London: Reaktion Books.

Merriman, P., Revill, G., Lorimer, H., Matless, D., Rose, G., \& Wylie, J. (2008) Landscape, mobility, practice. Social and Cultural Geography 9 (2): 191-212.

Merewether, J. (2018). New materialisms and children's outdoor environments: mumurative diffractions. Children's Geographies, doi.org/10.1080/14733285.2018.1471449

Mills, S., \& Kraftl, P. (2014). Introduction: Geographies, histories and practices of informal education. In S. Mills \& P. Kraftl (Eds.), Informal Education, Childhood and Youth: Geographies, Histories, Practices. Basingstoke: Palgrave Macmillan. pp. 1-18.

Mills, S., \& Kraftl, P. (2016). Cultural geographies of education. Cultural Geographies, 23(1): 19-27.

Morris, A. (2019). Educational landscapes and the environmental entanglement of humans and non-humans through the starling murmuration, The Geographical Journal, 185, xxx-xxx.

Moss, S. M. (2012). Natural Childhood. London: The National Trust.

Mycock, K. (2018). Playing with mud - becoming stuck, becoming free?... The negotiation of gendered/class identities when learning outdoors. Children's Geographies, doi.org/0.1080/ 4733285.2018 .1546379

Pacini-Ketchabaw, V., Taylor, A., \& Blaise, M. (2016). Decentring the Human in Multispecies Ethnographies. In C. Taylor \& C. Hughes (Eds.). Posthuman Research Practices in Education.

Philo, C. (1992) Neglected rural geographies: A review, Journal of Rural Studies 8 (2): 193207. 
Pimlott-Wilson, H., \& Coates, J. (2019). Rethinking learning?: Challenging and accommodating neoliberal educational agenda in the integration of Forest School into mainstream educational settings, The Geographical Journal, 185, xxx-xxx.

Rowley, W. R., Bezold, C., Arikan, Y., Byrne, E., \& Krohe, S. (2017). Diabetes 2030: Insights from Yesterday, Today, and Future Trends. Population Health Management, 20(1): 6-12.

Taylor, A. (2013). Reconfiguring the Natures of Childhood. New York: Routledge.

Tolia-Kelly, D. P. (2007) Fear in paradise: The affective registers of the English Lake District landscape re-visited. Senses and Society 2: 329-351.

\footnotetext{
1 'Nature Deficit Disorder' is a term coined by Richard Louv. It refers to the idea that human beings, especially children, are spending less time outdoors, and the belief that this results in negative consequences for their health, wellbeing and development. It is a contested topic and the focus of much attention in social commentaries and the wider field.
} 